\title{
Markers of Endothelial Activation and Impaired Autonomic Function in Patients with Acute Coronary Syndromes - Potential Prognostic and Therapeutic Implication
}

\author{
Arman Postadzhiyan, Anna Tzontcheva and Bojidar Finkov \\ Medical University, Clinic of Cardiology, St. Anne University Hospital, Sofia, \\ Bulgaria
}

\section{Introduction}

Atherosclerosis is increasingly considered as a low grade inflammatory response of the arterial wall to a variety of stimuli [Fuster\&Lewis, 1994; Libby, 2001]. It is accepted that the adhesion of circulating leukocytes and monocytes to endothelial cells (EC) and subsequent transendothelial migration are an important step in the initiation and the development of atherosclerotic lesions [Hillis\&Flapan, 1998; Jang, 1994]. This process is mediated by receptors expressed on the surface of vascular EC - cell adhesion molecules (CAM) under the action of an enhanced oxidative stress, lipopolysaccharide and proinflammatory cytokines. Vascular cell adhesion molecule (VCAM-1) and intercellular adhesion molecule (ICAM-1) are two members of the immunoglobulin gene superfamily that play important but different roles in the adhesion of blood cells to the vascular endothelium. The significance of these molecules in the course of atherogenesis is confirmed by their immunohistochemically established elevated expression in the atherosclerotic plaques [Cybulsky\&Gimbronejr, 1991; O’Brien et al., 1993] and by experimental models proving a delayed lesion development in case of their absence [Cybulsky et al., 2001].

Circulating forms of adhesion molecules that have been described are probably generated by cleavage to a site close to membrane insertion. The amount of ICAM-1 released has been demonstrated to be directly correlated with the surface expression of ICAM-1 in EC in culture and a correlation between plasma VCAM-1 and VCAM-1 mRNA has been reported in human atherosclerotic aorta [Leuwenberg et al., 1992; Pigott et al., 1992].

Levels of soluble cell adhesion molecules have been postulated to be useful risk predictor of cardiovascular events in healthy populations and various settings of ischemic heart disease [de Lemos et al., 2000; Hwang et al., 1997; Mulvihill et al., 2000, 2001; O'Malley et al., 2001; Ridker et al., 1998]. Nonetheless, the pathologic role of different soluble adhesion molecules in various stages of coronary artery disease is not fully defined.

Two electrocardiographic markers - ventricular arrhythmias (VA), [Bigger et al., 1981; Farrell et al., 1991; Kostis et al., 1987] and impaired cardiac autonomic function, as indicated by depressed heart rate variability (HRV), [Bigger at al., 1992; Farrell et all, 1991; 
Hartikainen et al., 1996; Kleiger et al., 1987; Lanza et al., 1998, 2006; La Rovere et al., 1998] have been shown to predict mortality among patients recovering from acute myocardial infarction (MI). However there are only limited data about the prognostic value of depressed HRV in the whole spectrum of patients with ACS and few attempts to quantify the exact value of soluble adhesion molecules and HRV in the cumulative risk assessment of patients with ACS [Kennon et al., 2008; Lanza et al., 2006].

Previous studies have shown that statin treatment improve the prognosis in patients with acute coronary syndromes [Kinlay et al., 2003; Ridker at al., 2005]. The reduction of clinical events secondary to lipid lowering has traditionally been attributed to reduction of cholesterol deposition and facilitation of cholesterol efflux from coronary plaques. However, several studies have recently suggested that the beneficial effects of statins in atherosclerotic disease may not be limited to the lipid-lowering effects of these drugs. Possible explanations for the observed reduction of morbidity and mortality with statin use include improvement of endothelial function, plaque stabilisation, and inhibition of the inflammatory response associated with atherosclerosis [Liao 2003; Ray\&Cannon, 2005]. In the last years an antiarrhythmic effect of statins has been suggested and reported as a possible contributing mechanism.

The aim of this study was:

1. To assess heart rate variability and soluble adhesion molecules ICAM-1 (intercellular adhesion molecule-1) and VCAM-1 (vascular cells adhesion molecule-1) in patients with coronary artery disease and healthy control and to evaluate the usefulness of the markers of impaired autonomic function and endothelial activation as predictors of adverse prognosis in patients with acute coronary syndromes.

2. The impact of early initiation of low and moderate-dose rosuvastatin treatment on autonomic function and concentrations of soluble adhesion molecules during the first 12 weeks post ACS without ST segment elevation.

\section{Methods}

\subsection{Study protocol}

The study consisted of two phases. In the first phase two groups of patients with coronary artery disease (acute coronary syndromes without ST segment elevation and stable angina pectoris) and one control group of subjects were included for comparisons of soluble levels of adhesion molecules and heart rate variability. Between December 2001 and July 2002, a total number of 136 patients were involved in the study. Patients were divided into three groups according to the clinical diagnosis. The first group consisted of 75 patients with non-ST segment elevation ACS (unstable angina and non ST elevation myocardial infarction). Unstable angina (UA) patients $(n=57)$ had ischemic chest pain at rest within the preceding 48 hours that had developed in the absence of an extracardiac precipitating cause with either ST segment depression of $>0.1 \mathrm{mV}$ or T wave inversion in two or more contiguous leads on the presenting 12 lead ECG. Patients with non ST elevation myocardial infarction $(n=18)$ had similar diagnostic criteria along with elevation of serum creatine kinase, without the evolution of pathological q waves. The second group consisted of 36 patients with stable angina pectoris (SAP) who had typical exertional angina pectoris and positive stress test. Patients with angina at rest were excluded from this group. The control group comprised of 25 healthy volunteers in the same age of distribution, without angina symptoms and with normal physical 
examination and stress test. Subjects with acute or chronic inflammatory diseases, malignancies, renal insufficiency, and severe liver disease, on immunosuppressive and antibiotic treatment were excluded from the study. Also excluded were patients with acute ST elevation myocardial infarction, diabetes mellitus, and history of myocardial infarction, surgical intervention or major trauma within the preceding month.

A six months follow-up of patients with ACS was assessed by regular clinical examination for every month. Primary outcome was defined as cardiac death, non-fatal myocardial infarction or recurrent hospital admission for severe unstable angina. After the 6-month period of observation the study population was divided into two groups - with favorable course of the disease and with occurrence of adverse coronary events.

In the second phase other 30 patients with ACS were allocated into two groups, and received rosuvastatin $10 \mathrm{mg} /$ day $(\mathrm{n}=16$, mean age $57.25 \pm 2.2$ years) or rosuvastatin 20 $\mathrm{mg} /$ day ( $\mathrm{n}=14$, mean age $57.64 \pm 3.1$ years). The randomization was carried out by the adaptive dynamic random allocation method irrespective of serum lipids levels. A followup assessment of both HRV on ambulatory ECG monitoring and adhesion molecules levels was performed during study period of 12 weeks. All patients were under treatment with the same medications during the acute phase of the episode (aspirin, nitrates, beta blockers, ACE inhibitors), according to the guidelines.

\subsection{Biochemical analysis}

Blood samples from ACS patients were collected after admission in the ICU prior to the onset of the antiischemic and anticoagulant therapy with a closed Vacutainer system (Beckton Dickinson, NJ, USA) and after 12 weeks for patients included into the second phase of the study. In SAP group and in controls, blood samples were collected at the time of clinical admission. The serum was separated after centrifugation at $3000 \mathrm{~g}$ for $10 \mathrm{~min}$ until 1 hour after taking the samples and sent in Department of Clinical Laboratory, Saint Anne University hospital for analyses of creatine kinase, cholesterol and triglycerides levels as a part of routine patient management. Two aliquots of the serum were centrally stored at $80^{\circ} \mathrm{C}$ and sent in batches to the Department of Clinical Laboratory and Clinical Immunology, Medical university, Sofia (for analyses of cTnT and hsCRP) and to the Section of Molecular Immunology, Bulgarian Academy of Sciences, Sofia (for analyses of VCAM-1 and ICAM-1). Determination of CTnT, hsCRP and soluble adhesion molecules levels was performed at the end of the study period, blinded to patients' histories and allocated treatment.

Quantitative detection of serum concentrations of sVCAM-1 and sICAM-1 was performed using an enzyme linked immunosorbent assay (ELISA) technique employing a commercially available assay kit (BenderMed Sysytems, Vienna, Austria). The intra- and interassay coefficients of variation were $3.1 \%, 5.2 \%$ for VCAM- 1 and $4.1 \%, 7.6 \%$ for ICAM- 1 respectively. The levels of cardiac troponin $\mathrm{T}(\mathrm{cTnT})$ were determined by a third generation troponin STAT electrochemiluminescent immunoassay on the ELECSYS 1010 (Roche Diagnostics, Basel, Switzerland) with the detection limit at $0.01 \mathrm{ng} / \mathrm{ml}$ and a total coefficient of variation $(\mathrm{CV})$ of $6 \%$ at $5.07 \mathrm{ng} / \mathrm{ml}$ and $9.3 \% \mathrm{CV}$ at $0.10 \mathrm{ng} / \mathrm{ml}$. High-sensitivity Creactive protein was measured with a CardioPhase hsCRP immunonephelometric assay (Dade Behring Inc) on BN systems. The detection limit was $0.175 \mathrm{mg} / 1$ with a total CV of $7.6 \%$ at $0.41 \mathrm{mg} / 1$. 


\subsection{Holter monitoring}

Patients underwent $24 \mathrm{~h}$ ECG Holter monitoring within $24 \mathrm{~h}$ of admission with two-channel tape recorders and monitoring two bipolar chest leads. Cardiac autonomic function was assessed by frequency-domain HRV analyses for the entire 24 hours. Frequency domain HRV was assessed in the frequency range of 0 to $0.5 \mathrm{~Hz}$ by fast-Fourier transform spectral analysis, with a spectral resolution of $0.0005 \mathrm{~Hz}$. The amplitude of the following frequencydomain HRV variables was obtained: very low frequency $(0.0033$ to $0.04 \mathrm{~Hz})$, low frequency $(0.04$ to $0.15 \mathrm{~Hz})$, and high frequency $(0.15$ to $0.40 \mathrm{~Hz})$. Further, the ratio of low to high frequency was calculated.

\subsection{Statistical analysis}

Any quantitative parameters under investigation were presented as a mean value and standart deviation. Any qualitative parameters under investigation were presented as a number and percentage. Student's $t$ test or paired sample t-test was used to compare the quantitative parameters in the groups with a normal distribution. Mann-Whitney's or Wilcoxon signed rank non-parametric analysis is applied to compare the quantitative parameters of non-Gaussian distribution such as cTnT, hsCRP, sICAM-1, sVCAM-1 and parameters of HRV. Comparison of the categorical variables was performed by Pearson's x2test and Fisher's test. Receiver-operating characteristics (ROC) analysis was performed to estimate the potential of the variable tested to discriminate between patients with and without cardiovascular events during follow-up. To identify variables as independent predictors of $\mathrm{CV}$ events we calculated various multivariate Cox regression models with stepwise adjustment for univariate predictors possibly confounding the examined variable. Probability values of $\mathrm{p}<0,05$ were considered statistically significant. All analyses were performed with SPSS, 9.0 version for Windows.

\section{Results}

\subsection{Markers of endothelial activation and impaired autonomic function in patients with acute coronary syndromes - Potential prognostic implication \\ 3.1.1 Characteristics of the study population}

Table 1 demonstrates clinical characteristics and biochemical data of all study groups. There were no significant differences among study groups regarding age, gender, family history and smoking status. The patients with coronary artery disease (acute coronary syndromes and stable angina) had significantly higher rates of hypertension and dyslipidaemia compared with healthy control group. The presence of coronary risk factors was equal among groups with acute coronary syndromes and stable angina pectoris. Eight of the patients in the control group (32\%) were on antihypertensive medications. The corresponding number of patients on antihypertensive medications in ACS group was 48 $(64 \%)$ and $21(61 \%)$ in stable angina pectoris group. All soluble ICAM-1, VCAM-1 and hsCRP significantly discriminated between patients with ACS and SAP ( $p=0.014,0.05$ and 0.025 respectively) and control subjects ( $\mathrm{p}<0.001,0.05$ and 0.048$)$. Soluble ICAM-1 and hsCRP were also elevated in patients with SAP compared with control group whereas no difference in sVCAM-1 was found ( $\mathrm{p}<0.001,0.05$ and 0.4$)$. In opposite, all the parameters of the frequency domain HRV tented to be lower in patients with ACS compared with stable angina and control group. In healthy subjects VLF, LF and HF were elevated, but LF/HF ratio was lower in comparison with stable angina patients $(\mathrm{p}=0.006)$. 
Markers of Endothelial Activation and Impaired Autonomic Function in Patients

\begin{tabular}{|l|c|c|c|c|c|c|}
\hline Variable & $\begin{array}{c}\text { ACS } \\
\text { Group 1 }\end{array}$ & $\begin{array}{c}\text { Stable AP } \\
\text { Group 2 }\end{array}$ & P1 & $\begin{array}{c}\text { Control } \\
\text { Group 3 }\end{array}$ & P2 & P3 \\
\hline Number & 75 & 36 & & 25 & & \\
\hline Age & $57.8 \pm 8.8$ & $57.8 \pm 8.7$ & 1 & $55.6 \pm 9.2$ & 0.3 & 0.4 \\
\hline Male gender & $41(54.7 \%)$ & $15(41.7 \%)$ & 0.2 & $12(48 \%)$ & 0.7 & 0.8 \\
\hline Family history & $36(48 \%)$ & $15(41.7 \%)$ & 0.5 & $11(44 \%)$ & 0.8 & 1 \\
\hline Hypertension & $51(68 \%)$ & $27(75 \%)$ & 0.5 & $11(44 \%)$ & 0.05 & 0.01 \\
\hline Smoking & $38(50.7 \%)$ & $14(38.9 \%)$ & 0.31 & $11(44 \%)$ & 0.65 & 0.8 \\
\hline $\begin{array}{l}\text { Cholesterol } \\
\text { mmol/1 }\end{array}$ & $6.24 \pm 1.25$ & $6.21 \pm 1.41$ & 0.92 & $5.41 \pm 0.79$ & 0.002 & 0.01 \\
\hline $\begin{array}{l}\text { Tryglycerides } \\
\text { mmol/1 }\end{array}$ & $1.94 \pm 1.06$ & $1.82 \pm 1.21$ & 0.62 & $1.27 \pm 0.42$ & 0.003 & 0.03 \\
\hline BMI>25 & $43(57.3 \%)$ & $26(72.2 \%)$ & 0.15 & $12(48 \%)$ & 0.49 & 0.06 \\
\hline Preivious MI & $19(25.3 \%)$ & $4(11.1 \%)$ & 0.13 & $0(0 \%)$ & 0.003 & 0.14 \\
\hline $\begin{array}{l}\text { sVCAM-1 } \\
\text { ng/ml }\end{array}$ & $1447.3 \pm 52.9$ & $1362.4 \pm 114.9$ & 0.05 & $1318.6 \pm 78.4$ & 0.05 & 0.419 \\
\hline $\begin{array}{l}\text { sICAM-1 } \\
\text { ng/ml }\end{array}$ & $465.5 \pm 15.9$ & $387.2 \pm 29.2$ & 0.014 & $108.6 \pm 14.7$ & $<0.001$ & $<0.001$ \\
\hline hsCRP mg/1 & $15.5 \pm 3.95$ & $2.33 \pm 0.39$ & 0.025 & $1.45 \pm 0.24$ & 0.048 & 0.05 \\
\hline VLF ms & $101.4 \pm 9.3$ & $195.2 \pm 45.3$ & 0.003 & $213.9 \pm 45.1$ & $<0.001$ & 0,78 \\
\hline LF ms & $71.1 \pm 8.05$ & $187.6 \pm 46.7$ & $<0.001$ & $199.7 \pm 43.5$ & $<0.001$ & 0.85 \\
\hline HF ms & $42.1 \pm 8.6$ & $87 \pm 27.6$ & 0.04 & $128.4 \pm 37.1$ & 0.001 & 0.37 \\
\hline LF/HF ms & $2.67 \pm 0.3$ & $4.09 \pm 0.7$ & 0.03 & $2.12 \pm 0.39$ & 0.43 & 0.06 \\
\hline
\end{tabular}

P1 group 1 vs group 2

P2 group 1 vs group 3

P3 group 2 vs group 3

Table 1. Baseline characteristics of study population

\subsubsection{Baseline characteristics of patients with ACS according to clinical outcome}

During the six month follow-up of the patients with acute coronary syndromes three patients $(4 \%)$ died suddenly, seventeen $(22.7 \%)$ suffered a non-fatal myocardial infarction and eight $(10.7 \%)$ had recurrent UA, for a major adverse cardiovascular event rate of $37.3 \%$. The majority of ischemic events occurred within 30 days of the initial episode of non ST elevation acute coronary syndrome - 16 (57.14\%). Simultaneously, the risk of development of non-fatal AMI and rehospitalization for recurrent UA remained significant even during a longer period of observation as $12(42,8 \%)$ of the subsequent complications occurred during the period between the 30th day and the 6th month.

On Table 2 the demographic, clinical and laboratory data of the patients with major cardiovascular events were compared with those of the patients with favorable outcome. Both groups do not differ concerning the classical risk factors for the development of ischemic heart disease such as age, gender, history of arterial hypertension, tobacco smoking, obesity, familial history and indices of lipid profile. The patients have received identical drug therapy including heparin $(97,3 \%)$, acetysal $(90,7 \%), \beta$-blocker $(73,3 \%)$, nitrate $(100 \%)$, ACE-inhibitor (48\%) and diuretics (17,3\%). The patients with subsequent complications presented more often with Killip class over $1(28,6 \%$ versus $8,5 \%, p=0,047)$ 
and with a significantly lower left ventricular ejection fraction on the echocardiographic examination performed between day 3 and day 7 of the hospitalization $(54,6 \%$ versus $60,4 \%$, $\mathrm{p}=0,003)$. Concentrations of sVCAM-1 $(1488,75 \mathrm{ng} / \mathrm{ml}$ versus $1071,45 \mathrm{ng} / \mathrm{ml}, \mathrm{p}<0,001)$, sICAM-1 (516,7 vs 433,3 ng/ml, p=0,010), hsCRP (32.6 vs $5.31 \mathrm{mg} / \mathrm{l}, \mathrm{p}=0.001)$ and cTnT $(0,72$ vs $0,115 \mathrm{ng} / \mathrm{ml}, \mathrm{p}<0,001)$ at presentation were significantly raised in patients who went on to have ischemic events during the six months of follow-up. None of the parameters of HRV was significantly associated with the occurrence of the composite endpoint. Although the prognostic information of frequency domain HRV indices was low, we found out that 2 variables - reduced LF $(27 \pm 1.7$ vs $65.1 \pm 10 \mathrm{~ms}, \mathrm{p}=0.05)$ and $\mathrm{LF} / \mathrm{HF}$ ratio $(0.5 \pm 0.2$ vs $2.94 \pm 0.4$, $\mathrm{p}=0.004$ ) were significantly predictive of death, but no for other endpoints (Fig 1)

\begin{tabular}{|c|c|c|c|}
\hline & $\begin{array}{c}\text { No event } \\
n(\%)\end{array}$ & $\begin{array}{l}\text { Event } \\
\mathrm{n}(\%)\end{array}$ & $\mathrm{p}$ \\
\hline Number & 47 & 28 & \\
\hline Males & $26(55.3)$ & $15(53.6)$ & 1 \\
\hline Age, y & $57.36 \pm 8.2$ & $58.6 \pm 10.1$ & 0.559 \\
\hline Hypertension & $34(72.3)$ & $17(60.7)$ & 0.318 \\
\hline Smoking & $23(48.9)$ & $15(53.6)$ & 0.812 \\
\hline Previous MI & $12(25.5)$ & $7(25)$ & 1 \\
\hline Family history & $20(42.6)$ & $16(57.1)$ & 0.242 \\
\hline $\mathrm{BMI}>25$ & $25(53.2)$ & $18(64.3)$ & 0.470 \\
\hline Kilip $>1$ & $4(8.5)$ & $8(28.6)$ & 0.047 \\
\hline Cholesterol mmol/1 & $6.30 \pm 1.22$ & $6.13 \pm 1.31$ & 0.581 \\
\hline Triglycerides mmol/1 & $2.07 \pm 1.19$ & $1.70 \pm 0.75$ & 0.145 \\
\hline Ejection fraction $\%$ & $60.4 \pm 7.65$ & $54.6 \pm 8.45$ & 0.003 \\
\hline Troponin T ng/ml & $0.115 \pm 0.01$ & $0.72 \pm 0.16$ & $<0.001$ \\
\hline hsCRP mg/l & $5.31 \pm 1.66$ & $32.59 \pm 9.45$ & 0.001 \\
\hline sVCAM-1 ng/ml & $1071.5 \pm 54.08$ & $1488.8 \pm 90.3$ & $<0.001$ \\
\hline sICAM-1 ng/ml & $433.3 \pm 20.01$ & $516.7 \pm 23.8$ & 0.010 \\
\hline VLF ms & $114.5 \pm 13.4$ & $89.2 \pm 11.6$ & 0.16 \\
\hline LF ms & $73.7 \pm 12.2$ & $65.2 \pm 10.1$ & 0.62 \\
\hline HF ms & $56.6 \pm 16.4$ & $32.5 \pm 6.5$ & 0.143 \\
\hline LF/HF ms & $1.98 \pm 0.3$ & $2.98 \pm 0.4$ & 0.07 \\
\hline
\end{tabular}

Table 2. Baseline characteristics of patients with and without cardiovascular events during follow-up 

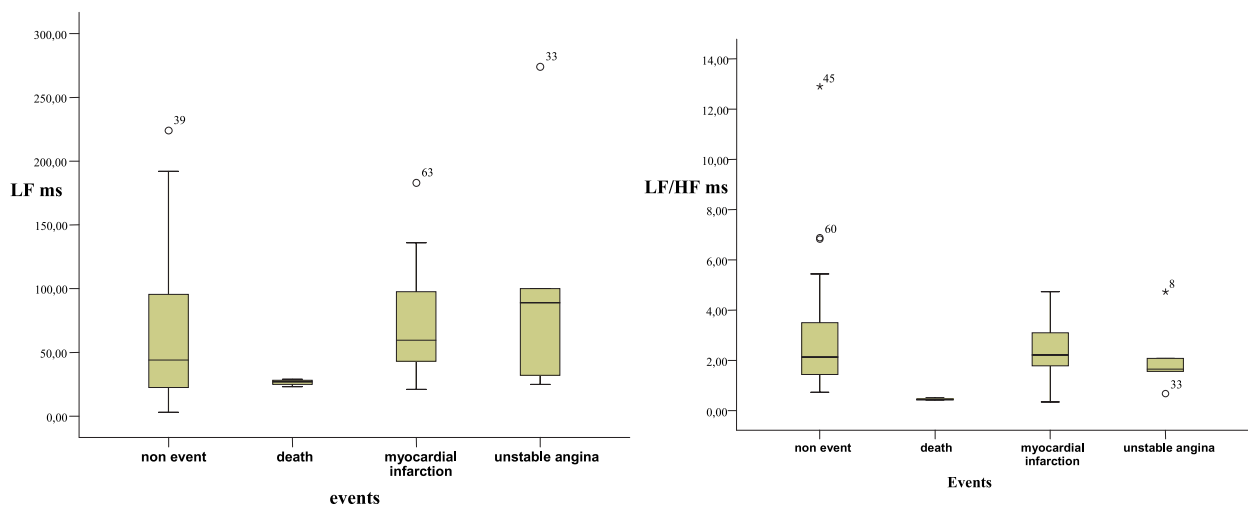

Fig. 1. LF and LF/HF in patients according to the prognosis during the study period

Table 3 presents the associations between soluble adhesion molecules, high sensitivity Creactive protein and troponin $\mathrm{T}$ in patients with ACS. There is a moderately strong positive correlation between the levels of sICAM-1 and sVCAM-1 (Spearman's r=0,205, $p=0,028$ ). Levels of sICAM-1 showed a strong correlation with hsCRP. The correlation between sVCAM-1 and hsCRP was $r=0.144, p=0.11$. In acute coronary syndromes levels of the myocardial necrosis marker troponin $\mathrm{T}$ correlated highly significant with hsCRP ( $\mathrm{r}=0.451$, $\mathrm{p}=0.001)$, but showed no interdependence with sVCAM-1 $(\mathrm{r}=0.106, \mathrm{p}=0.383)$ and sICAM-1 $(\mathrm{r}=0.129, \mathrm{p}=0.286)$.

\begin{tabular}{|l|c|c|c|c|}
\hline & & sVCAM-1 & sICAM-1 & hsCRP \\
\hline sVCAM-1 & $\mathrm{r}$ & 1 & 0,205 & 0,144 \\
\hline sICAM-1 & $\mathrm{p}$ & - & 0,028 & 0,11 \\
\hline & $\mathrm{r}$ & 0,205 & 1 & 0,438 \\
\hline hsCRP & $\mathrm{p}$ & 0,028 & - & $<0,001$ \\
\hline & $\mathrm{r}$ & 0,144 & 0,438 & 1 \\
\hline cTnT & $\mathrm{p}$ & 0,11 & $<0,001$ & - \\
\hline & $\mathrm{r}$ & 0,106 & 0,129 & 0,451 \\
\hline
\end{tabular}

Table 3. Associations between soluble adhesion molecules, high sensitivity C-reactive protein and troponin $\mathrm{T}$

A nonsignificant inverse correlation was found between sVCAM-1 levels and all HRV variables studied with the strongest association with low frequency amplitude. The correlation coefficients of hsCRP and cTnT with HRV parameters were low and without clinical significance. (table 4) 


\begin{tabular}{|l|c|c|c|c|c|}
\hline & & VLF & LF & HF & LF/HF \\
\hline hsCRP & $\mathrm{r}$ & 0,128 & $-0,02$ & 0,16 & $-0,19$ \\
\hline & $\mathrm{p}$ & 0,35 & 0,87 & 0,24 & 0,16 \\
\hline sVCAM-1 & $\mathrm{r}$ & $-0,10$ & $-0,24$ & $-0,12$ & $-0,06$ \\
\hline & $\mathrm{p}$ & 0,46 & 0,08 & 0,41 & 0,67 \\
\hline sICAM-1 & $\mathrm{r}$ & $-0,08$ & 0,014 & 0,03 & 0,009 \\
\hline & $\mathrm{p}$ & 0,55 & 0,92 & 0,82 & 0,95 \\
\hline cTnT & $\mathrm{r}$ & 0,125 & 0,017 & 0,15 & $-0,07$ \\
\hline & $\mathrm{p}$ & 0,36 & 0,9 & 0,27 & 0,57 \\
\hline
\end{tabular}

Table 4. Associations between HRV and soluble adhesion molecules, high sensitivity Creactive protein and troponin $\mathrm{T}$

\subsubsection{Soluble adhesion molecules and cardiovascular events}

The ROC analysis was performed to provide an index for assessment of the accuracy of the variable investigated to discriminate between subjects with cardiovascular complications and those without it. The data obtained from it demonstrate threshold concentrations of 0,01 $\mathrm{ng} / \mathrm{ml}$ for cTnT (area under the curve 0,803, $\mathrm{p}=0,001$ ), $4 \mathrm{mg} / 1$ for hsCRP (AUC 0,859, $\mathrm{p}=0,001$ ), $1153,4 \mathrm{ng} / \mathrm{mL}$ for sVCAM-1 (AUC 0,786, $\mathrm{p}=0,001$ ) and $438 \mathrm{ng} / \mathrm{mL}$ for sICAM-1 (AUC 0,671, p=0,017) Fig 2.
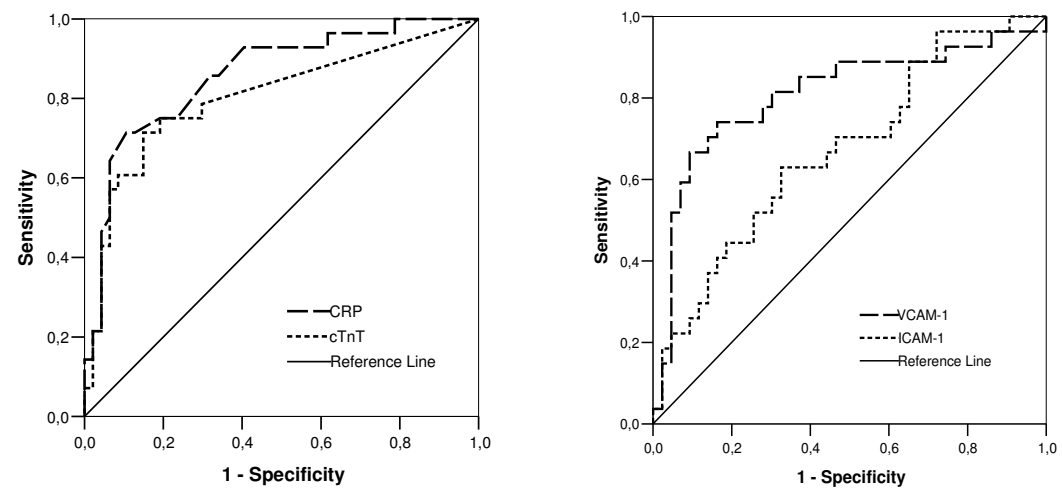

\begin{tabular}{|l|c|c|c|c|}
\hline \multicolumn{1}{|c|}{ Variable } & AUC & SE & \multicolumn{2}{c|}{$95 \%$ Confidence Interval } \\
\hline CRP & 0,859 & 0,045 & 0,770 & 0,948 \\
\hline cTnT & 0,803 & 0,057 & 0,692 & 0,914 \\
\hline VCAM-1 & 0,786 & 0,059 & 0,669 & 0,902 \\
\hline ICAM-1 & 0,671 & 0,066 & 0,542 & 0,800 \\
\hline
\end{tabular}

AUC - area under the curve, SE - standard error

Fig. 2. Receiver-operator characteristic curves of the investigated biomarkers as a test for predicting major adverse coronary events in patients with acute coronary syndromes 
A total of 37 patients (49.3\%) had a concentration of sVCAM-1>1153.4 ng/ml and the ischemic event rate for these patients was $78.6 \%$. The remaining 38 patients had sVCAM-1 concentrations $<1153.4 \mathrm{ng} / \mathrm{ml}$ and the ischemic event rate in this group was $21.4 \%$ (Pearson $\mathrm{x} 2=15,28, \mathrm{p}<0,001)$. As Figure 3 A shows the difference was mainly driven by an increased rate of non-fatal myocardial infarction and rehospitalsation for unstable angina in the group of patients with high sVCAM-1 levels. Although the incidence rate of the ischemic complications in the patients with sICAM-1>438 ng/ $\mathrm{ml}$ was $66,7 \%$ while in the patients with subthreshold concentration of this parameter it was only $33,3 \%$, a statistically reliable difference was lacking (Pearson $x 2=2,71, p<0,140$, Figure 3 B). The sensitivity of a concentration of sVCAM-1 $>1153.4$ $\mathrm{ng} / \mathrm{ml}$ for predicting future ischemic events was $79 \%$, with a specificity of $68 \%$. The negative predictive value was $84 \%$. The sensitivity of sICAM-1>438 ng/ml for predicting a future ischemic events was $66 \%$, with a specificity of $53 \%$ and negative predicting value of $72 \%$.

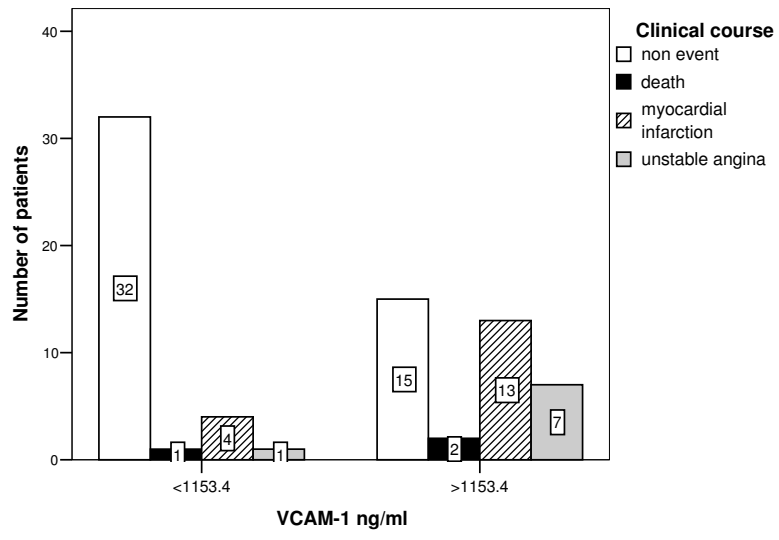

a

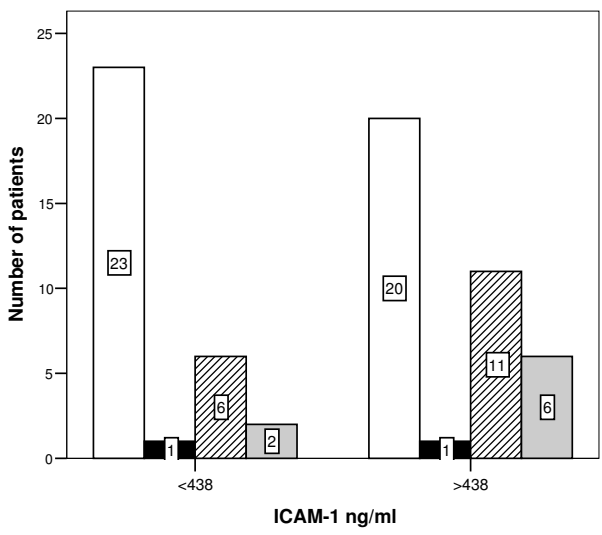

$\mathrm{b}$

Fig. 3. Cardiovascular events in patients according to concentration of sVCAM-1 (A) and sICAM-1 (B) 


\subsubsection{Multivariate risk stratification}

In a multivariate analysis that included baseline characteristics and biochemical markers (Table 5) sVCAM-1 remained an independent and powerful predictor of increased cardiac risk at 6 months follow-up. The odds ratio associated with the highest value of sVCAM-1 was 4.62 (95\% CI 1.8-11.4, $\mathrm{p}=0.0009)$ without adjustment and remained significantly elevated after adjustment for Killip class and left ventricular ejection fraction in model 2 (RR 4.63, 1.811.7, $\mathrm{p}=0.0012)$, troponin $\mathrm{T}$ in model $3(\mathrm{RR} 3.93,1,5-10, \mathrm{p}=0.04)$ and C-reactive protein in model 4 (RR 2.22, 0.8-5.7, p=0.05) Figure 4.

\begin{tabular}{|l|c|c|c|}
\hline & Odds ratio & $95 \%$ CI & P \\
\hline Sex - Males & 0.93 & $0.44-1.97$ & 0.86 \\
\hline Age $>65 \mathrm{y}$ & 1.48 & $0.68-3.21$ & 0.31 \\
\hline Hypertension & 1.38 & $0.64-2.96$ & 0.39 \\
\hline Smoking & 1.11 & $0.52-2.34$ & 0.77 \\
\hline BMI $>$ 25 & 1.38 & $0.6-2.9$ & 0.41 \\
\hline Hypercholesterolemia & 1.11 & $0.45-2.76$ & 0.80 \\
\hline Family history & 1.58 & $0.7-3.34$ & 0.23 \\
\hline Previous MI & 1.00 & $0.42-2.37$ & 0.98 \\
\hline ST depression $>0.5 \mathrm{~mm}$ & 2.11 & $0.85-5.2$ & 0.10 \\
\hline Killip $>1$ & 2.73 & $1.19-6.22$ & 0.016 \\
\hline EF $<50 \%$ & 2.75 & $1.24-6.11$ & 0.0125 \\
\hline ICAM-1 > 438 ng/ml & 1.81 & $1.82-4.04$ & 0.15 \\
\hline VCAM-1 > $1153.4 \mathrm{ng} / \mathrm{ml}$ & 4.62 & $1.86-11.4$ & 0.0009 \\
\hline hSCRP $>4 \mathrm{mg} / 1$ & 9.85 & $3.39-28.5$ & $<0.0001$ \\
\hline cTnT $>0.01 \mathrm{ng} / \mathrm{ml}$ & 5.29 & $2.13-13.1$ & 0.0003 \\
\hline
\end{tabular}

Table 5. Univariate Cox proportional regression analyses

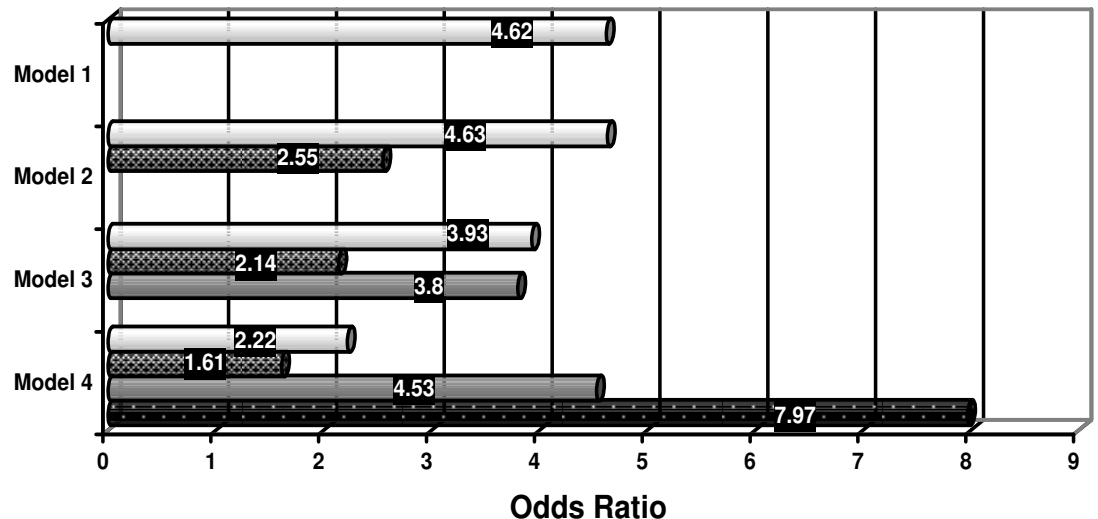

- CRP $>4 \mathrm{mg} / \mathrm{l} \quad \square \mathrm{cTnT}>0.01 \mathrm{ng} / \mathrm{ml} \quad$ 圈Killip $>1 \& E F<50 \% \quad$ VVCAM $>1153.4 \mathrm{ng} / \mathrm{ml}$

Fig. 4. Multivarate Cox regression models on VCAM-1 as predictor of major adverse coronary events during 6 month follow-up 
In order to assess the exact role of the increased soluble adhesion molecules levels we analyzed the combined predictive value of these two molecules with that of the already established prognostic indicators among ACS patients - troponin T and hs C-reactive protein. Division of the patients into 4 groups based on their SCAM and cTnT levels revealed that SVCAM-1 is an independent prognostic indicator of major adverse coronary events during the six months follow-up. In the patients admitted to the ICU without any detectable levels of the marker of cardiomyocyte necrosis $(n=39)$ the incidence rate of the ischemic events was 1,3\% when combined with low levels of sVCAM-1 and 6,7\% when combined with sVCAM-1 $>1153,4 \mathrm{ng} / \mathrm{ml}$ (Pearson $x^{2}=6,03, p<0,024$, Figure 5 A). Simultaneously, the high sICAM-1 levels do not improve the prognostic value of troponin T as there was no statistically significant difference in the incidence rate of the complications in the patients with a negative cTnT test in dependence on the low or high sICAM-1 levels (the incidence of the complications was 2,9\% and 5,7\%, respectively) (Figure 5 B).
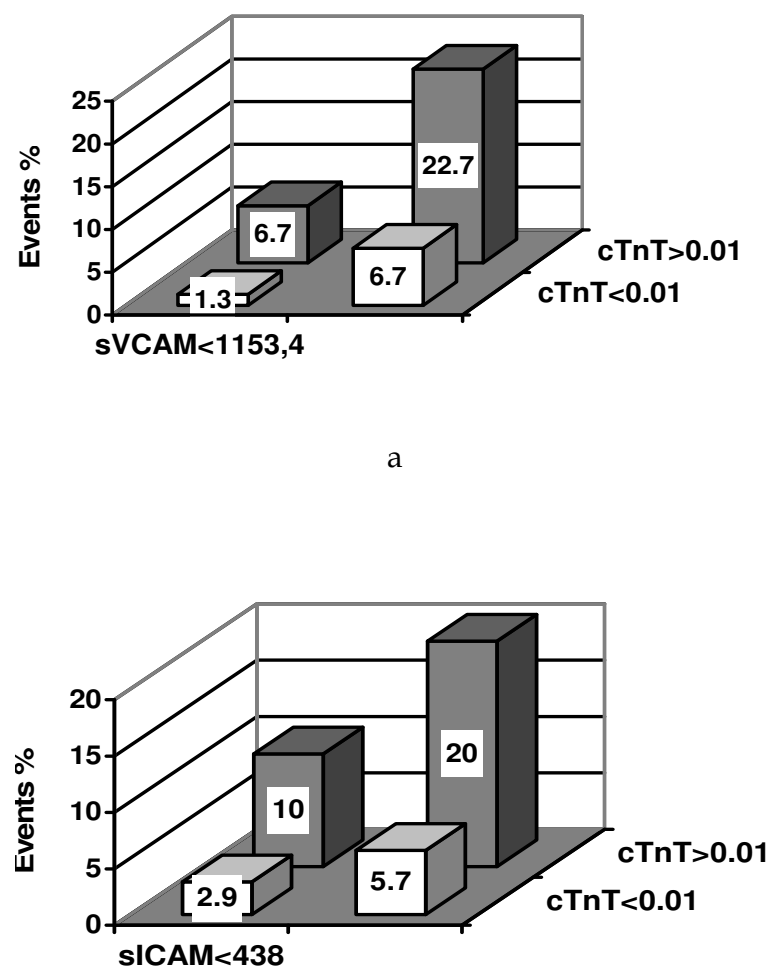

b

Fig. 5. Incidence of cardiovascular events according to soluble VCAM-1 and cTnT levels (A) and soluble ICAM-1 and cTnT levels (B) 
Furthermore, the predictive value of VCAM-1 was independent of systemic inflammation as evidenced by C-reactive protein. High VCAM-1 serum levels indicated increased cardiac risk both in patients with high CRP serum levels $(25.3 \% \%$ vs $6.7 \%, \mathrm{p}=0.024)$ and in those with low CRP serum levels ( $4 \%$ vs $1.3 \%$, p=0.05), Figure 6 .

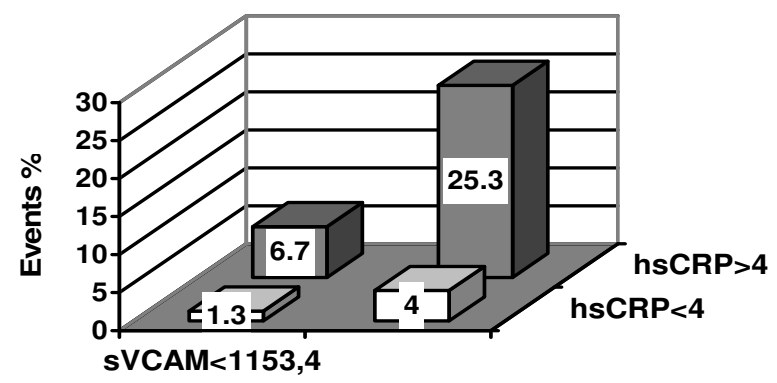

a

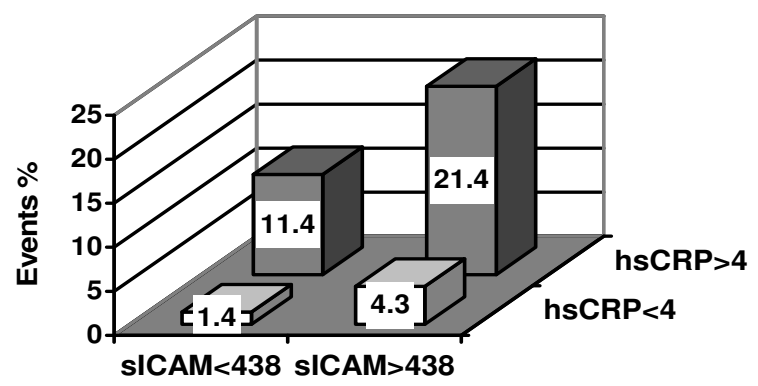

b

Fig. 6. Incidence of cardiovascular events according to soluble VCAM-1 and hsCRP levels (A) and soluble ICAM-1 and hsCRP levels (B) 


\subsection{Markers of endothelial activation and impaired autonomic function in patients with acute coronary syndromes - Potential therapeutic implication 3.2.1 Characteristics of the study population}

During the second phase of the study 30 patients with ACS were allocated into two groups, and received rosuvastatin $10 \mathrm{mg} /$ day ( $\mathrm{n}=16$, mean age $57.25 \pm 2.2$ years) or rosuvastatin 20 $\mathrm{mg} /$ day ( $\mathrm{n}=14$, mean age $57.64 \pm 3.1$ years) for 12 weeks. Baseline characteristics for each group are presented in Table 6, showing no significant differences between the two treatment groups. Furthermore, no significant differences in lipids, HRV and markers of endothelial activation were observed at baseline.

\begin{tabular}{|c|c|c|c|}
\hline Variable & $\begin{array}{l}\text { Rosuvastatin } \\
10 \mathrm{mg} \\
\mathrm{n}=16\end{array}$ & $\begin{array}{c}\text { Rosuvastatin } \\
20 \mathrm{mg} \\
\mathrm{n}=14\end{array}$ & $\mathrm{p}$ \\
\hline Age & $57,25 \pm 2,22$ & $57,64 \pm 3,1$ & 0.34 \\
\hline Male gender & $7(23 \%)$ & $9(30 \%)$ & 0.22 \\
\hline Hypertension & $9(30 \%)$ & $9(30 \%)$ & 0.72 \\
\hline Smoking & $7(23.3 \%)$ & $6(20 \%)$ & 0.62 \\
\hline Family history & $5(16.7 \%)$ & $7(23.3 \%)$ & 0.46 \\
\hline cTnT & $0,29 \pm 0.13$ & $0,46 \pm 0,18$ & 0.91 \\
\hline $\mathrm{EF} \%$ & $58,5 \pm 2,1$ & $58,8 \pm 2,6$ & 0.46 \\
\hline BMI & $26,8 \pm 1$ & $26,9 \pm 1$ & 0.34 \\
\hline Cholesterol mmol/1 & $5,66 \pm 0,28$ & $6,07 \pm 0,32$ & 0.4 \\
\hline Tryglycerides mmol/1 & $1,76 \pm 0,17$ & $1,93 \pm 0,25$ & 0.6 \\
\hline HDL-C mmol/1 & $0,99 \pm 0,03$ & $0,91 \pm 0,03$ & 0.14 \\
\hline LDL-C mmol/1 & $3,86 \pm 0,29$ & $4,27 \pm 0,28$ & 0.3 \\
\hline sVCAM-1 ng/ml & 1235(831.3-1476.3) & $1327,4(1039.5-1989.7)$ & 0.21 \\
\hline sICAM-1 ng/ml & $476,8(424,3-516,8)$ & $439,4(362,1-607,3)$ & 0.92 \\
\hline VLF ms & $97 \pm 18,7$ & $90,7 \pm 16,7$ & 0.80 \\
\hline LF ms & $43,3 \pm 8,2$ & $44,5 \pm 7,1$ & 0.91 \\
\hline HF ms & $19,8 \pm 5,8$ & $20,9 \pm 6,7$ & 0.89 \\
\hline LF/HF ms & $3,34 \pm 0,5$ & $3,58 \pm 0,5$ & 0.77 \\
\hline
\end{tabular}

Table 6. Baseline characteristics 


\subsubsection{Effects of rosuvastatin on lipid profile and markers of endothelial and autonomic activation}

The changes in lipid values from baseline to 12 weeks in the two treatment groups are shown in Table 7.

\begin{tabular}{|l|c|c|c|c|c|c|}
\hline & \multicolumn{3}{|c|}{ Rosuvastatin $10 \mathrm{mg}$} & \multicolumn{3}{c|}{ Rosuvastatin 20 mg } \\
\hline & Baseline & 3 months & $\mathrm{p}$ & Baseline & 3 months & $\mathrm{p}$ \\
\hline $\begin{array}{l}\text { Cholesterol } \\
\text { mmol/1 }\end{array}$ & $5,66 \pm 0,28$ & $4,49 \pm 0,18$ & $<0.001$ & $6,07 \pm 0,32$ & $4,24 \pm 0,16$ & $<0.001$ \\
\hline $\begin{array}{l}\text { Tryglycerides } \\
\text { mmol/1 }\end{array}$ & $1,76 \pm 0,17$ & $1,3 \pm 0,13$ & $<0.001$ & $1,93 \pm 0,25$ & $1,37 \pm 0,18$ & $<0.001$ \\
\hline HDL-C mmol/1 & $0,99 \pm 0,03$ & $1,05 \pm 0,04$ & $<0.001$ & $0,91 \pm 0,03$ & $1,06 \pm 0,03$ & $<0.001$ \\
\hline LDL-C mmol/1 & $3,86 \pm 0,29$ & $2,67 \pm 0,2$ & $<0.001$ & $4,27 \pm 0,28$ & $2,27 \pm 0,11$ & $<0.001$ \\
\hline
\end{tabular}

Table 7. Effects of rosuvastatin on lipid profile

Serum levels of total cholesterol, triglycerides and LDL-cholesterol in patients decreased after 3 months of treatment with rosuvastatin. The decrease in total cholesterol and LDL cholesterol was significantly larger in the more aggressively treated group ( $\mathrm{p}<0.05$ for all comparisons).

\begin{tabular}{|c|c|c|c|c|c|c|}
\hline & \multicolumn{3}{|c|}{ Rosuvastatin $10 \mathrm{mg}$} & \multicolumn{3}{|c|}{ Rosuvastatin $20 \mathrm{mg}$} \\
\hline & Baseline & 3 months & $\mathrm{p}$ & Baseline & 3 months & $\mathrm{p}$ \\
\hline $\begin{array}{l}\text { sVCAM-1 } \\
\text { median ng/ml } \\
\text { 25- and 75- } \\
\text { percentile }\end{array}$ & $\begin{array}{c}1235 \\
(831.3- \\
1476.3) \\
\end{array}$ & $\begin{array}{c}1120,2 \\
(839,7- \\
1341,2)\end{array}$ & 0.43 & $\begin{array}{c}1327,4 \\
(1039.5-1989.7)\end{array}$ & $\begin{array}{l}962,4 \\
(603,4- \\
1570,3) \\
\end{array}$ & 0,01 \\
\hline $\begin{array}{l}\text { sICAM-1 } \\
\text { median ng/ml } \\
\text { 25- and 75- } \\
\text { percentile }\end{array}$ & $\begin{array}{c}476,8 \\
(424,3-516,8)\end{array}$ & $\begin{array}{c}385,5 \\
(348,5-453,9)\end{array}$ & 0,004 & $\begin{array}{c}439,4 \\
(362,1-607,3)\end{array}$ & $\begin{array}{c}324,7 \\
(188,5-447,5)\end{array}$ & 0.01 \\
\hline VLF ms & $97 \pm 18,7$ & $99,5 \pm 16,5$ & 0,8 & $90,7 \pm 16,7$ & $113,3 \pm 20,5$ & 0,35 \\
\hline LF ms & $43,3 \pm 8,2$ & $63,8 \pm 14,9$ & 0,2 & $44,5 \pm 7,1$ & $56,7 \pm 13,4$ & 0,23 \\
\hline HF ms & $19,8 \pm 5,8$ & $37 \pm 11,6$ & 0,23 & $20,9 \pm 6,7$ & $42,2 \pm 7,2$ & 0,009 \\
\hline LF/HF ms & $3,34 \pm 0,5$ & $2,87 \pm 0,5$ & 0,31 & $3,58 \pm 0,5$ & $1,73 \pm 0,2$ & 0,003 \\
\hline
\end{tabular}

Table 8. Effects of Rosuvastatin on Adhesion Molecules and HRV levels

After 3 months, patients in the $20 \mathrm{mg}$ rosuvastatin group demonstrated a significant decrease in serum levels of sICAM-1 and sVCAM-1 (Table 8, Figure 7 and 8). Also in the 10 mg-rosuvastin group, there was a significant decrease of sICAM-1 (Figure 9). However, no changes in sVCAM-1 levels were observed in this group of patients (Table 8, Figure 10). There were no significant differences in changes between the two treatment groups for either soluble adhesion molecules levels, but for sICAM-1 we found out a trend towards lower concentrations in the moderately treated group $(\mathrm{p}=0.07)$.

No correlations were found between changes in LDL-cholesterol over 12 weeks and changes in s-ICAM-1 ( $\mathrm{r}=0.198, \mathrm{p}=0.29)$, sVCAM-1 $(\mathrm{r}=0.193, \mathrm{p}=0.31)$ and HRV during the same period. The Spearman's correlation coefficients between hsCRP and sICAM-1 ( $r=0.059, p=0,7)$ and sVCAM-1 $(r=0.15, p=0,4)$ are low and not statistically significant. 


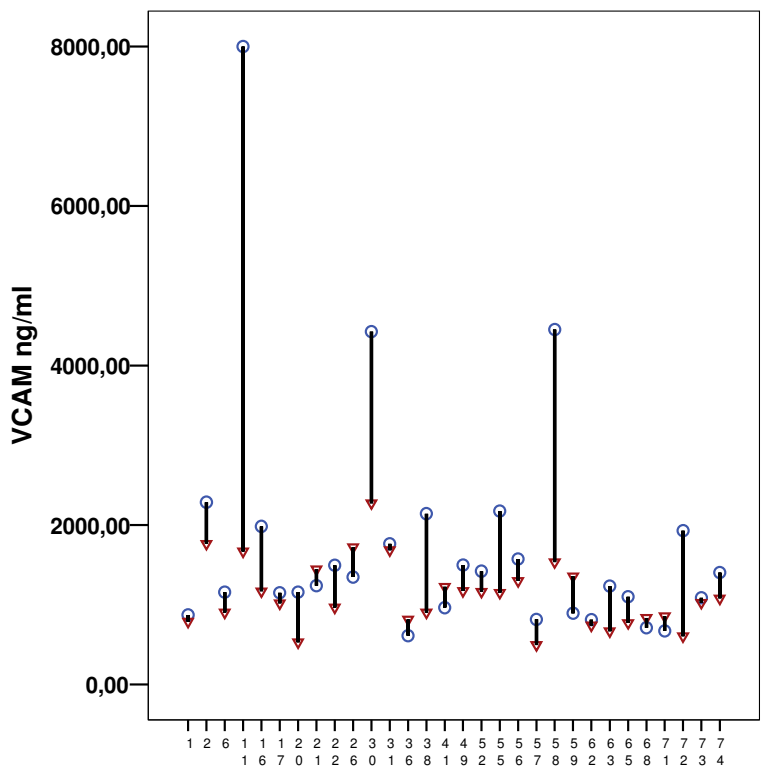

vcam_1

$\nabla$ vcam_statin

Case Number

Fig. 7. Intra-individual changes in levels of s-VCAM-1 in patients during the study.

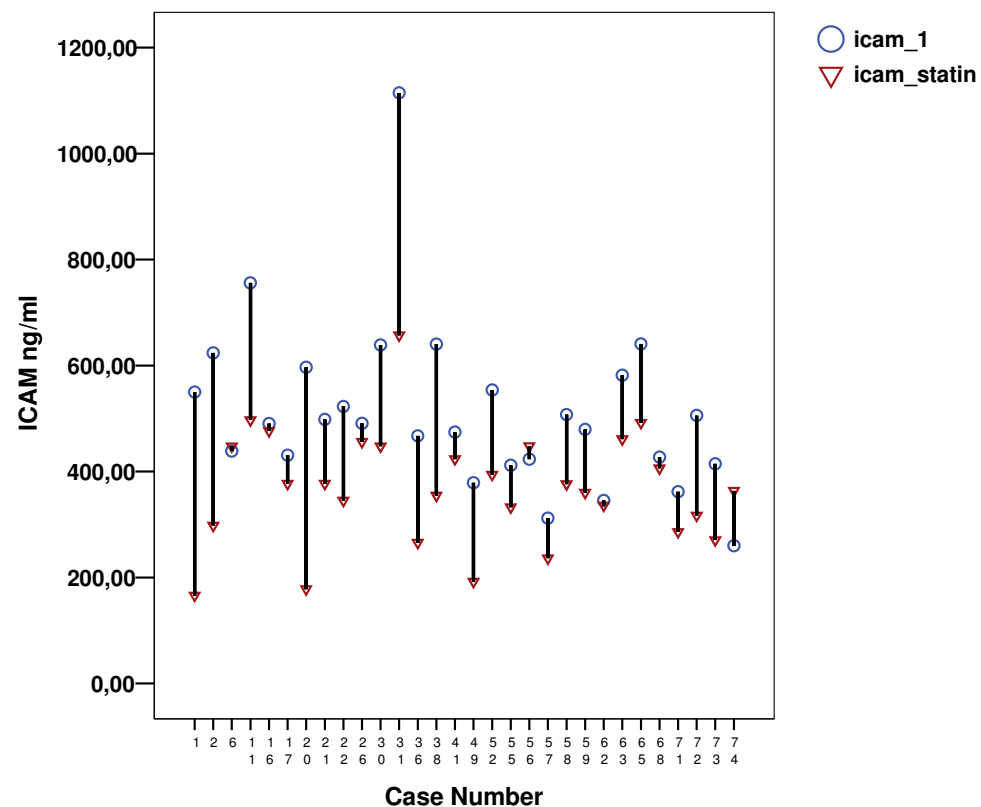

Fig. 8. Intra-individual changes in levels of s-ICAM-1 in patients during the study. 


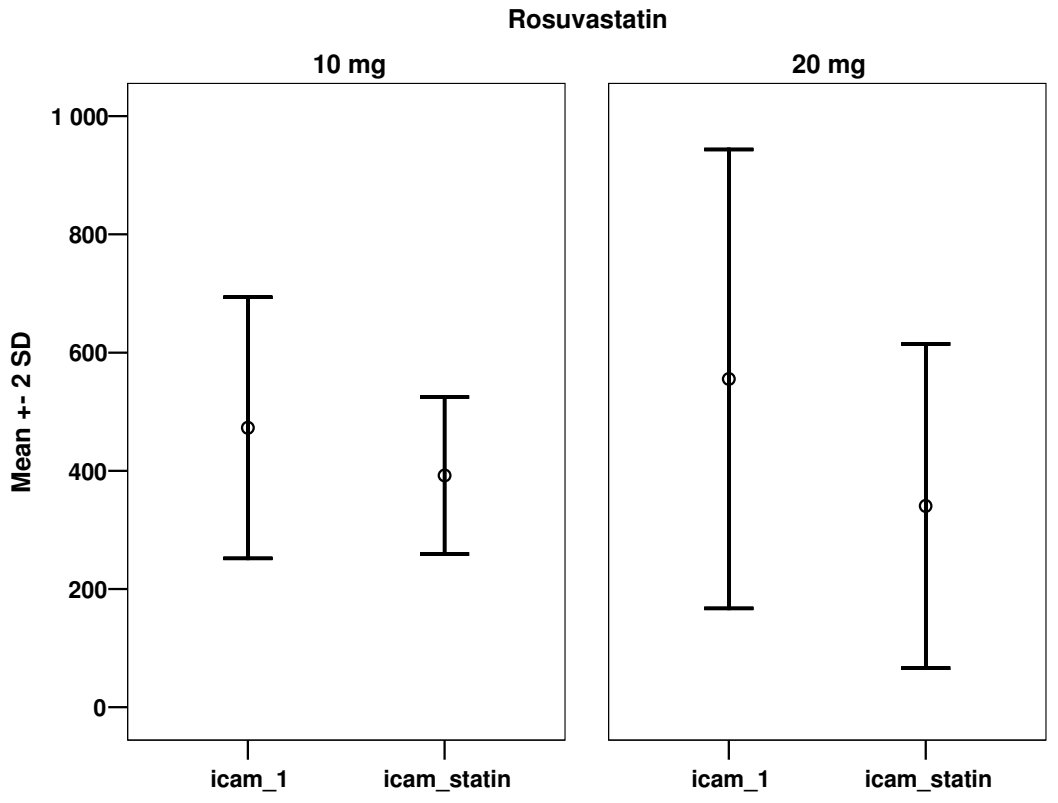

Fig. 9. Mean changes \pm 2 SD of sICAM-1 in the two rosuvastatin treated groups

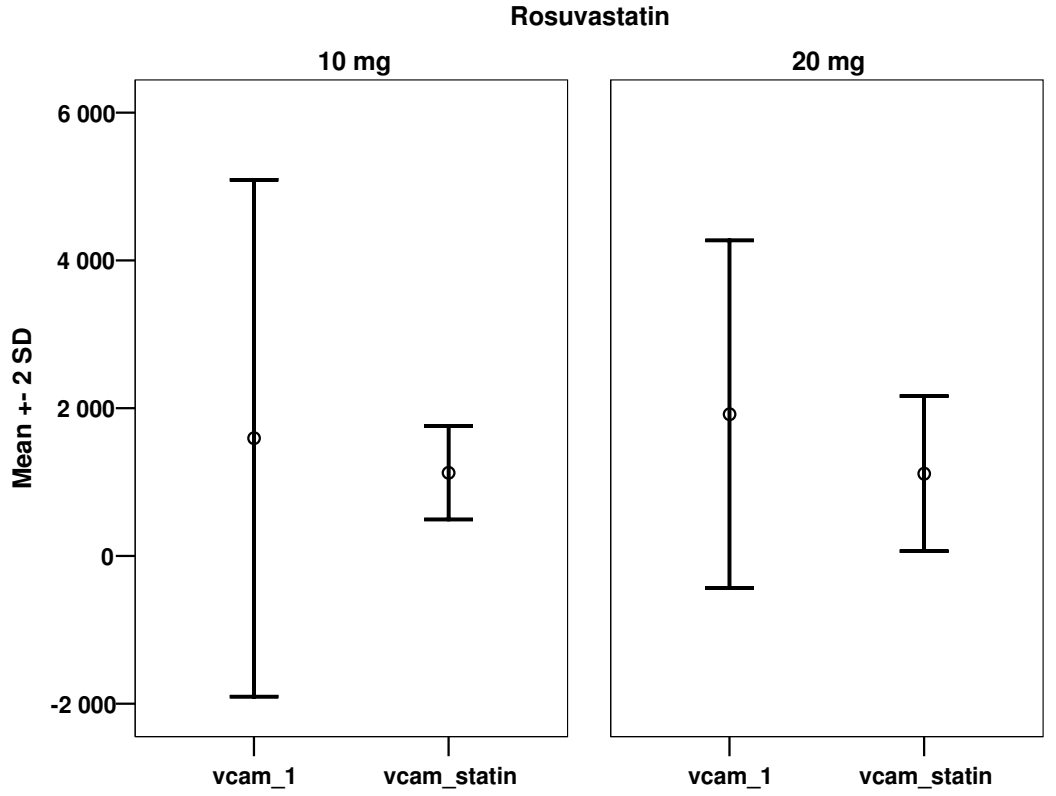

Fig. 10. Mean changes \pm 2 SD of sVCAM-1 in the two rosuvastatin treated groups 
In ACS group, a significant inverse correlation was observed between markers of endothelial activation and HRV variables, with the strongest association being found for sVCAM-1 and HF amplitude $(r=-0.506, p=0.004)$ and LF amplitude $(r=-0,4, p=0.02)$. In addition, sympathovagal balance was shifted to greater vagal predominance with $20 \mathrm{mg}$ rosuvastatin (increase of HF and decrease of low frequency/ high frequency ratio) when compared to lower dose of $10 \mathrm{mg}, \mathrm{p}=0.05$, Table 9 .

\begin{tabular}{|c|c|c|c|c|c|c|c|c|c|}
\hline & & & LDL & $\begin{array}{c}\text { vcam } \\
1\end{array}$ & $\begin{array}{c}\text { icam } \\
1\end{array}$ & VLF & $\mathrm{LF}$ & $\mathrm{HF}$ & $\mathrm{LF} / \mathrm{HF}$ \\
\hline \multirow{14}{*}{$\begin{array}{l}\text { Spearman's } \\
\text { rho }\end{array}$} & \multirow{2}{*}{ LDL } & $\begin{array}{l}\text { Correlation } \\
\text { Coefficient }\end{array}$ & 1,000 & 193 & 198 & ,049 & ,029 & 130 &,- 098 \\
\hline & & Sig. (2-tailed) & & ,308 & ,294 & 804 & ,882 & ,509 & 620 \\
\hline & \multirow{2}{*}{ vcam 1} & $\begin{array}{l}\text { Correlation } \\
\text { Coefficient }\end{array}$ & 193 & 1,000 &, $384\left(^{*}\right)$ &,- 158 & $423\left(^{-}\right)$ &,- 506 & 207 \\
\hline & & Sig. (2-tailed) & 308, & . & ,036 & 405, & 020 & ,004 & ,273 \\
\hline & \multirow{2}{*}{ icam 1} & $\begin{array}{l}\text { Correlation } \\
\text { Coefficient }\end{array}$ & 198 &, $384\left(^{*}\right)$ & 1,000 & ,089 &,- 144 &,- 234 & ,210 \\
\hline & & Sig. (2-tailed) & 294, & ,036 & . & 654, & ,465 & 231 & ,284 \\
\hline & \multirow{2}{*}{ VLF } & $\begin{array}{l}\text { Correlation } \\
\text { Coefficient }\end{array}$ & ,049 &,- 158 & ,089 & 1,000 & ,694 &, $431\left(^{*}\right)$ & ,125 \\
\hline & & Sig. (2-tailed) & 804 & ,405 & 654 & & ,000 & ,017 & ,511 \\
\hline & \multirow{2}{*}{ LF } & $\begin{array}{l}\text { Correlation } \\
\text { Coefficient }\end{array}$ & ,029 & $423\left(^{*}\right)$ &,- 144 & 694 & 1,000 & 656 & ,091 \\
\hline & & Sig. (2-tailed) & 882, & 020 & 465 & 000, & . & ,000 & 634 \\
\hline & \multirow{2}{*}{$\mathrm{HF}$} & $\begin{array}{l}\text { Correlation } \\
\text { Coefficient }\end{array}$ & 130 &,- 506 &,- 234 & $431\left(^{*}\right)$ & 656 & 1,000 &,- 649 \\
\hline & & Sig. (2-tailed) & 509, & ,004 & 231, & 017, & ,000 & . & ,000 \\
\hline & \multirow{2}{*}{$\mathrm{LF} / \mathrm{HF}$} & $\begin{array}{l}\text { Correlation } \\
\text { Coefficient }\end{array}$ &,- 098 & 207 & 210 & 125 & ,091 &,- 649 & 1,000 \\
\hline & & Sig. (2-tailed) & 620, & 273, & 284 & 511, & 634 & ,000 & \\
\hline
\end{tabular}

* Correlation is significant at the 0.05 level (2-tailed).

Table 9. Associations between HRV and soluble adhesion molecules and LDL cholesterol 


\section{Discussion}

The measurement of ICAM-1 and VCAM-1 in prospective studies is based on the presence of an inflammatory process in the artery wall which increases the expression of adhesion molecules and on the hypothesis that the serum levels of these molecules reflect their expression by the endothelial cells. In this study we had measured the two main representatives of the immunoglobulin gene superfamily of CAM and found significantly higher levels of both sVCAM-1 and sICAM-1 in patients with ACS as compared with those with SAP and healthy controls. Our finding that soluble adhesion molecules and especially sVCAM-1 are strongly and independently predictive for future CV events in patient with ACS extends previous observations describing the predictive value of inflammatory markers on future cardiac events. However, whereas the causative role of C-reactive protein in promoting the inflammatory component in development of plaque rupture remains controversial, our data implicate a direct mediator of an inflammatory vessel wall process. Several arguments support the hypothesis that sCAM may be more useful than other markers of inflammation in predicting clinical outcome:

First, all sICAM-1 and sVCAM-1 measured in our study are elevated in patients at risk for future cardiovascular events. Second, sCAM levels did not correlate with cTnT, a specific marker of cardiomyocyte necrosis and the most established prognostic marker in patients with ACS. The risk related to the high SVCAM-1 concentrations is independent of the cTnT that is evident from the increasing rate of complications in the groups with negative and positive cTnT in dependence on sVCAM-1 levels. These data suggest that VCAM-1 release actually precedes myocardial injury and that VCAM-1 elevation identifies patients with unstable atherosclerotic plaque formation even before complete microvascular obstruction. In contrast, we do not find any relationship between sICAM-1 and the risk of subsequent events in the course of the follow-up and we do not read any enhanced incidence rate of vascular events in the patients without laboratory evidence of a cardiomyocyte necrosis in dependence on the levels of this parameter. Third, sVCAM-1 levels did not correlate with Creactive protein, a systemic marker of inflammation. Because hsCRP correlated with cTnT levels elevated CRP serum levels most likely reflect both a robust vascular inflammatory response and myocardial injury. The measurement of sVCAM-1 added to the predictive value of hsCRP in determining the risk of future cardiovascular events. Even patients with low hsCRP levels were found to be at significantly higher risk with elevated sVCAM-1 levels which suggest that endothelial activation and proteolytic cleavage of SCAM is a primary event and is followed by release of other systemic mediators and acute phase proteins such as C-reactive protein.

Prospective data of soluble adhesion molecules are sparse. The results of our study correspond to the data published in the literature about the relationship between SCAM and the risk of cardiovascular events and they find their explanation in some differences between the two adhesion molecules studied. In the large prospective trials ARIC and PHS of healthy individuals, sICAM-1, but not sVCAM-1 appears consistently related to incident CAD [de Lemos et al., 2000; Hwang et al., 1997; Ridker et al., 1998]. ICAM-1 expression is not only endothelial and ICAM-1 is constitutively expressed by a variety of cell types including cells of the hematopoietic lineage and fibroblasts. sICAM-1 correlates with acute phase reactants like CRP and provides similar predictive information to CRP in settings of primary prevention [Blankenberg et al., 2003; Mulvihill et al., 2002; Ridker et al., 1998; 2000]. sICAM-1 therefore appears as a general marker of a proinflammatory status with little 
prognostic information in patients with ACS after controlling the data for troponin T and Creactive protein (Figure 5 and 6). By contrast, VCAM-1 is not expressed in baseline condition, but is rapidly induced by pro-atherosclerotic conditions in animal models and humans [Cybulsky\&Gimbronejr, 1991; O'Brien et al., 1993]. It seems that sVCAM-1 represents an appropriate marker of plaque burden or activity of a potential clinical importance as a prognostic indicator under the conditions of secondary prevention rather than in healthy individuals without endothelial dysfunction [Blankenberg et al., 2003; Mulvihill et al., 2002]. A similar hypothesis is supported by the data proving the independent predictive value of sVCAM-1 in the patients with angiographically proven coronary artery disease [Blankenberg et al., 2001], with diabetes mellitus [Jager et al., 2000] and with ACS [Mulvihill et al., 2001, 2002] as well as its absence in healthy individuals [de Lemos et al., 2000].

The relationship between depressed HRV and mortality is difficult to ascertain as the exact physiological mechanisms responsible for the various HRV components are still incompletely known [Task Force of the European Society of Cardiology and the North American Society of Pacing and Electrophysiology, 1996; Tsuji et al., 1996]. Decreased values of HRV variables, including LF, may reflect reduced vagal tone or predominant sympathetic influence to the heart. The presence of frequent or complex non-sustained VA in the context of sympathovagal imbalance can increase the susceptibility to fatal VA, in particular during myocardial ischaemia [Kent et al., 1973; Lanza et al., 1998, 2006; Schwartz et al.,1988]. On the other hand, VA and depressed HRV are unlikely to be associated with the triggers of acute MI, as they were not predictive of non-fatal MI in hospital or at six-month follow up.

Recent experimental findings have suggested that the nervous autonomic system can significantly modulate inflammatory reactions [Wang et al., 2003]. In particular, vagal stimulation has been shown to decrease inflammatory reactions in animals by inhibiting tissue macrophage activation, an effect mediated by stimulation of the alpha-7 subunit of the macrophage nicotine receptor by the vagal neurotransmitter acetylcholine, whereas adrenergic activity has been reported to favor sympathectomy and towards inflammatory reactions. Conversely, several products of inflammation have been shown to have potential influence on nervous autonomic activity by central and/or peripheral mechanisms [Lanza et al.,2006; Tracey,2002]. The low and no significant correlations between markers of endothelial activation and HRV in the present study emphasize that neural influence unlikely explained the observed predictive value of soluble adhesion molecules in patients with ACS.

ACS is a diffuse process involving the entire coronary vasculature [Buffon et al., 2002]. Although mechanical revascularization by percutaneous coronary intervention may address the culprit lesion, recurrent events may reflect disease progression or instability elsewhere in the vascular tree. Stabilization of vulnerable plaques or modulation of the so-called vulnerable patient is becoming recognized as an important target for systemic therapy [Libby\&Aikawa 2003; Naghavi et al., 2003a, 2003b]. The rapid pleiotropic effects of statins on inflammation, endothelial function, and coagulation are likely to be particularly beneficial in patients with ACS in whom these systems are deranged.

Inhibition of HMG CoA reductase by statins inhibits cholesterol synthesis and isoprenoid production. This results in reduced prenylation of small G-proteins such as Rho and, in turn, NF-KB activation. By inhibiting HMG CoA reductase, statins can prevent the biosynthesis of 
isoprenoids such as farnesyl pyrophosphate and geranylgeranyl pyrophosphate. Inhibition of Rho geranylgeranylation by statins can reduce leukocyte adhesion and fibronolytic activity [Rasmussen et al., 2003; Yoshida et al.,2001]. A recent report suggests additional mechanism which is independent of mevalonate production - statins bind to a novel allosteric site within the B2-integrin leukocyte function-associated antigen-1 (LFA- 1), preventing binding to the counterreceptor on the endothelial surface (ICAM-1) [WeitzSchmidt et al., 2001].

In addition, statins can induce endothelial nitric oxide synthase (eNOS) accumulation in endothelial cells, an effect dependent on the inhibition of Rho geranylgeranylation, reduce the activation of monocyte/macrophage system, the cytotoxicity of T-lymphocytes and the balance between Th-1/Th-2 subclass. Hence, statins modify the immune response in ACS via reductions in inflammatory cell number, adhesion, and activation at potentially vulnerable sites along the wall [Liao, 2002; Libby\&Aikawa 2003].

In animal models HMG-CoA reductase inhibitors have been shown to reduce renal sympathetic nerve traffic [Pliquett et al., 2003]. To date, the underlying mechanism by which statins reduce sympathetic outflow has not been elucidated. An effect on central nitric oxide (NO) and reactive oxygen species (ROS) formation, as well as regulation of the AT1-receptor expression, have been proposed as possible explanations [Gao et al., 2005; Gomes et al., 2010; Hirooka et al., 2010; Patel et al., 2001].

Contradictory results have been published about the effect of statins on sICAM-1 and sVCAM-1 plasma/serum concentrations in patients with various clinical manifestation of ischemic heart disease. In a number of small population studies, different authors have noted that treatment with statins diminished sICAM-1 concentrations in subjects with hypercholesterolemia or CHD [Ascer et al., 2004; Patti et al., 2006]. However, Wiklund et al., 2002 observed a small and inconsistent effect of simvastatin and atorvastatin treatment in hypercholesterolemic patients. Furthermore, Jilma et al., 2003, demonstrated that atorvastatin, simvastatin, or pravastatin did not modify sICAM-1 concentrations after 3 months of treatment in subjects with moderate hypercholesterolemia. Blanco-Colio et al. 2007, investigate the effect of 10-, 20-, 40- and 80 mg Atorvastatin on sICAM-1 and MCP-1 levels in 2117 patients with CHD in Achieve Cholesterol Targets Fast with Atorvastatin Stratified Titration Trial and didn't found statistically significant differences between the various doses used. Although atorvastatin had a weak effect on sICAM-1 concentrations in the whole population [ $-2.2 \%$ change (95\% confidence interval -3.8 to $-0.6 \%)$; $\mathrm{P}=.006$ ], in the highest quartile all doses of atorvastatin diminished sICAM-1 plasma levels by more than $10 \%$ in subjects at high cardiovascular risk, indicating that atorvastatin has a greater effect in subjects with higher systemic inflammation. In the large PROVE-IT TIMI 22 study Ray et al. 2006 didn't found significant difference between intensive $(80 \mathrm{mg}$ Atorvastatin) and standart (40 mg Pravastatin) regiment on sICAM-1 levels at 30 days. However, when considered the relation among statin therapy, sICAM-1 levels, and clinical outcomes, the authors found that the risk of adverse events for patients with a sICAM-1 level $>231 \mathrm{ng} / \mathrm{ml}$ appeared more marked among those allocated to standard dose statin therapy (each odds ratio >2.1). The observed pattern raises the hypothesis that the risk associated with sICAM-1 may be attenuated by treatment with intensive statin therapy (each odds ratio <1.5).

In this study we have analyzed the effect of two rosuvastatin regimens on sICAM-1 and sVCAM-1 concentration in patients with high risk ACS defined by the levels of soluble 
adhesion molecules. We observed that the treatment with rosuvastatin diminish both markers of endothelial activation during 12 week follow-up. We found out a trend towards lower concentrations of sICAM-1 in patients randomized to $20 \mathrm{mg}$ Rosuvastatin, in addition to the previously observed significant lowering of low-density lipoprotein and C-reactive protein. There was no correlation between sCAMs and low-density lipoprotein and hsCRP at month 3 and the effect of rosuvastatin on soluble CAMs did not appear to be explained by changes in lipids or inflammatory markers.

However, standart statin therapy did not significantly alter sVCAM-1 levels at 3 months. The present observations with sVCAM-1 are analogous to the observations with aspirin and clopidogrel in which each drug decreases the risk of adverse clinical events in subjects with high CRP levels but do not decrease CRP significantly [Chew et al., 2001; Kennon et al., 2001; Ridker et al., 1997]. A potential mechanistic explanation for our clinical observations is, that among subjects with increased endothelial activation, a more potent statin regimen could bind to lymphocyte function-associated antigen- 1 on inflammatory cells to a greater extent, thus interfering with downstream effects of increased endothelial activation rather than decreasing endothelial activation itself. This hypothesis raises the possibility that novel therapeutic strategies that target inhibition of adhesion molecules may be of benefit in ACS, as has been demonstrated in animal models and in patients with inflammatory bowel disease [Gill et al., 2005; Van Assche et al., 2005].

An interesting finding was the observed beneficial effect of more intense statin regiment on some parameters of autonomic function. During the study period we found out a significant increase of high frequency component with represents the parasympathetic contribution to the spectrum, whereas low frequency remained unchanged. As a result, the LF/HF ratio, measure of autonomic balance was reduced significantly in patients received $20 \mathrm{mg}$ Rosuvastatin. The results of the correlation analysis clearly suggest that some of the beneficial effects of more potent statin dose may be driven by the effect on endothelial and autonomic function [Lanza et al., 2006; Patti et al., 2006]. Supports for this hypothesis are the results of the meta-analysis of Patti et al, who found that high-dose statin pretreatment before percutaneous coronary intervention leads to a significant reduction in periprocedural myocardial infarction and 30-day adverse events. It is noteworthy that the effect is most pronounced, but is not limited in patients with elevated markers of inflammatory activity [Patti et al., 2011]. Our findings must be confirmed by larger studies. It may contribute to the achievement of specific treatment goals for each patient with proper drug selection and dose titration in high risk patients such as those with elevated markers of endothelial activation and depressed HRV.

\section{Conclusions}

In patients with ACS, soluble adhesion molecules are independent predictors of subsequent MACE and reduced HRV of medium-term mortality, suggesting that markers of endothelial activation and impaired autonomic function should be taken into account in the risk stratification of these patients.

Our findings support the hypothesis that statins decrease endothelial injury and activation in patients with acute coronary syndromes. In addition we found that more aggressive regiment with early initiation of $20 \mathrm{mg}$ Rosuvastatin significantly decreases sICAM-1 levels 
and better preserve parasympathetically mediated variable of HRV. Future studies are required to elucidate the optimal dose of statin treatment in patients with ACS and high levels of markers of inflammatory and endothelial activation or impaired autonomic function.

\section{References}

Ascer E, Bertolami MC, Venturinelli ML, et al (2004). Atorvastatin reduces proinflammatory markers in hypercholesterolemic patients. Atherosclerosis, Vol. 177, pp. 161 -6.

Bigger JT, Weld FM, Rolnitzki LM (1981). Prevalence, characteristics and significance of ventricular tachycardia (three or more complexes) detected with ambulatory electrocardiographic recording in the late hospital phase of acute myocardial infarction. Am J Cardiol, Vol. 48, pp.815-23.

Bigger JT, Fleiss JL, Steinman RC, et al (1992). Frequency-domain measures of heart period variability and mortality after myocardial infarction. Circulation, Vol. 85, pp. 16471.

Blankenberg S, Rupprecht HJ, Bickel C, Peetz D, Hafner G, Tiret L, et al. (2001) Circulating cell adhesion molecules and death in patients with coronary artery disease. Circulation, Vol. 104: pp. 1336-42.

Blankenberg S, Barbaux S, Tiret L (2003). Adhesion molecules and atherosclerosis. Atherosclerosis, Vol. 170, pp. 191-203

Blanco-Colio LM, Martın-Ventura JL, de Teresa E, Farsang C, Gaw A, et all of the ACTFAST investigators (2007). Elevated ICAM-1 and MCP-1 plasma levels in subjects at high cardiovascular risk are diminished by atorvastatin treatment. Atorvastatin on Inflammatory Markers study: A substudy of Achieve Cholesterol Targets Fast with Atorvastatin Stratified Titration. Am Heart J, Vol. 153, pp. 881-8.

Buffon A, Biasucci LM, Liuzzo G, D'Onofrio G, Crea F, Maseri A (2002). Widespread coronary inflammation in unstable angina. $N$ Engl J Med, Vol. 347, pp. 5-12.

Chew DP, Bhatt DL, Robbins MA, Mukherjee D, Roffi M, Schneider JP, Topol EJ, Ellis SG (2001). Effect of clopidogrel added to aspirin before percutaneous coronary intervention on the risk associated with C-reactive protein. Am J Cardiol, Vol.88, pp.672- 674 .

Cybulsky MI\&Gimbronejr MA (1991). Endothelial expression of a mononuclear leukocyte adhesion molecule during atherogenesis. Science, Vol. 251, pp. 788-91.

Cybulsky MI, Iiyama K, Li H et al (2001). A major role for VCAM-1, but not ICAM-1, in early atherosclerosis. J Clin Invest, Vol. 107, pp. 1255-1262

de Lemos JA, Hennekens CH, Ridker PM (2000). Plasma concentration of soluble vascular cell adhesion molecule-1 and subsequent cardiovascular risk. J Am Coll Cardiol, Vol. 36, pp. 423-6.

Farrell TG, Bashir Y, Cripps T, et al.(1991). Risk stratification for arrhythmic events in postinfarction patients based on heart rate variability, ambulatory electrocardiographic variables and the signal-averaged electrocardiogram. J Am Coll Cardiol, Vol. 18, pp. 687-97.

Fuster V.\&Lewis A. (1994). Conner Memorial Lecture. Mechanisms leading to myocardial infarction: insights from studies of vascular biology. Circulation, Vol. 90, pp. 21262146 . 
Gao L, Wang W, Li YL, Schultz HD, Liu D, Cornish KG, et al (2005). Simvastatin therapy normalizes sympathetic neural control in experimental heart failure: Roles of angiotensin II type 1 receptors and NAD(P)H oxidase. Circulation, Vol. 112, pp.1763 $-1770$.

Gill V, Doig C, Knight D, Love E, Kubes P (2005). Targeting adhesion molecules as a potential mechanism of action for intravenous immunoglobulin. Circulation, Vol. 112, pp. 2031-2039.

Gomes, ME; Tack, CT; Verheugt, FW at al (2010). Sympathoinhibition by Atorvastatin in Hypertensive Patients. Circ J, Vol. 74, pp. 2622 - 2626

Hartikainen JEK, Malik M, Staunton A, et al (1996). Distinction between arrhythmic and nonarrhythmic death after acute myocardial infarction based on heart rate variability, signal-averaged electrocardiogram, ventricular arrhythmias and left ventricular ejection fraction. J Am Coll Cardiol, Vol. 28, pp. 296-304.

Hillis GS\&Flapan AD (1998). Cell adhesion molecules in cardiovascular disease: a clinical perspective. Heart, Vol. 79, pp. 429- 431.

Hirooka Y, Sagara Y, Kishi T, Sunagawa K (2010). Oxidative stress and central cardiovascular regulation: Pathogenesis of hypertension and therapeutic aspects. Circ J, Vol. 74, pp. $827-835$.

Hwang SJ, Ballantyne CM, Sharrett AR, Smith LC, Davis CE, Gottojr AM, et al. (1997). Circulating adhesion molecules VCAM-1, ICAM-1 and E-selectin in carotid atherosclerosis and incident coronary heart disease cases: the Atherosclerosis Risk In Communities (ARIC) study. Circulation, Vol. 96, pp. 4219-25.

Jager A, van Hinsbergh VW, Kostense PJ, Emeis JJ, Nijpels G, Dekker JM, et al. (2000) Increased levels of soluble vascular cell adhesion molecule 1 are associated with risk of cardiovascular mortality in type 2 diabetes: the Hoorn study. Diabetes, Vol. 49, pp. 485-91.

Jang Y, Lincoff AM, Plow EF, Topol EJ (1994). Cell adhesion molecules in coronary artery disease. J Am Coll Cardiol, Vol. 24, pp. 1591- 601.

Jilma B, Joukhadar C, Derhasching U, et al (2003). Levels of adhesion molecules do not decrease after 3 months of statin therapy in moderate hypercholesterolemia. Clin Sci (Lond), Vol. 104, pp. 189 - 93.

Kennon S, Price CP, Mills PG, Ranjadayalan K, Cooper J, Clarke H, Timmis AD (2001). The effect of aspirin on C-reactive protein as a marker of risk in unstable angina. J Am Coll Cardiol, Vol. 37, pp. $1266-1270$.

Kennon S, Price CP, Mills PG et al (2003). Cumulative risk assessment in unstable angina: clinical, electrocardiographic, autonomic, and biochemical markers. Heart, Vol. 89, pp36-41

Kent KM, Smith ER, Redwood DR, et al (1973). Electrical stability of acutely ischemic myocardium: influences of heart rate and vagal stimulation. Circulation, Vol. 47, pp. 291-8.

Kinlay S, Schwartz GG, Olsson AG, et al. (2003). Myocardial Ischemia Reduction with Aggressive Cholesterol Lowering Study Investigators. High-dose atorvastatin enhances the decline in inflammatory markers in patients with acute coronary syndromes in the MIRACL study. Circulation, Vol. 108, pp. 1560-1566. 
Kleiger RE, Miller JP, Bigger JT et al., The Multicenter Postinfarction Research Group, (1987). Decreased heart rate variability and its association with increased mortality after acute myocardial infarction. Am J Cardiol, Vol. 59, pp. 256-62.

Kostis JB, Friedman LM, Goldstein S et al., for the BHATB Study Group, (1987). Prognostic significance of ventricular ectopic activity in survivors of acute myocardial infarction. J Am Coll Cardiol, Vol. 10, pp. 231-42.

Lanza GA, Guido V, Galeazzi MM, et al (1998). Prognostic role of heart rate variability in patients with a recent acute myocardial infarction. Am J Cardiol, Vol. 82, pp. 1323-8.

Lanza GA, Cianflone D, Rebuzzi AG, et al. for the Stratificazione Prognostica dell'Angina Instabile Study Investigators (2006). Prognostic value of ventricular arrhythmias and heart rate variability in patients with unstable angina. Heart, Vol. 92, pp.1055-1063;

Lanza, GA, Sguegliaa GA, Cianflone D et al. for the SPAI (Stratificazione Prognostica dell'Angina Instabile) Investigators (2006). Relation of Heart Rate Variability to Serum Levels of C-Reactive Protein in Patients With Unstable Angina Pectoris. Am J Cardiol, Vol. 97, pp. 1702-1706

La Rovere MT, Bigger JT Jr, Marcus FI, et al (1998). Baroreflex sensitivity and heart rate variability in prediction of total cardiac mortality after myocardial infarction. ATRAMI (autonomic tone and reflexes after myocardial infarction) investigators. Lancet, Vol. 351, pp.478-84.

Leuwenberg JF, Smeets EF, Neefjes JJ et al (1992). E-selectin and intercellular adhesion molecule-1 are relased by activated human endothelial cells in vitro. Immunology, Vol. 77, pp. 543-9.

Liao JK (2002). Beyond lipid lowering: the role of statins in vascular protection. Int J Cardiol, Vol. 86, pp. 5-18.

Libby P. (2001). Current concepts of the pathogenesis of the acute coronary syndromes. Circulation, Vol. 104, pp. 365-372

Libby P\&Aikawa M (2003). Mechanisms of plaque stabilization with statins. Am J Cardiol, Vol. 91(suppl 4A), pp. 4B-8B.

Mulvihill N, Foley JB, Murphy R et al (2000). Evidence of prolonged inflammation in unstable angina and non Q wave myocardial infarction. J Am Coll Cardiol, Vol. 36, pp 1210-6.

Mulvihill N, Foley JB, Murphy R et al (2001). Risk stratification in unstable angina and nonQ-wave myocardial infarction using soluble cell adhesion molecules. Heart, Vol. 85, pp. 623-627

Mulvihill N, Foley JB, Crean P, Walsh M (2002). Prediction of cardiovascular risk using soluble cell adhesion molecules. Eur Heart J, Vol. 23, pp. 1569-1574

Naghavi M, Libby P, Falk E, Casscells SW, Litovsky S, Rumberger J, Badimon JJ, Stefanadis C, Moreno P, Pasterkamp G, et al (2003). From vulnerable plaque to vulnerable patient: a call for new definitions and risk assessment strategies, part I. Circulation, Vol. 108, pp. $1664-1672$.

Naghavi M, Libby P, Falk E, Casscells SW, Litovsky S, Rumberger J, Badimon JJ, Stefanadis C, Moreno P, Pasterkamp G, et al (2003). From vulnerable plaque to vulnerable patient: a call for new definitions and risk assessment strategies, part II. Circulation, Vol. 108, pp. 1772-1778.

O'Brien KD, Allen MD, McDonald TO, Chait A, Harlan JM,Fishbein D, et al. (1993). Vascular cell adhesion molecule-1 is expressed inhuman coronary atherosclerotic plaques. 
Implications for the mode of progression of advanced coronary atherosclerosis. $J$ Clin Invest, Vol. 92, pp. 945-51.

O'Malley T, Ludlam CA, Riemermsa RA, Fox K (2001). Early increase in levels of soluble intercellular adhesion molecule-1 (sICAM-1). Potential risk factor for the acute coronary syndromes. Eur Heart J, Vol. 22, pp. 1226-34

Patel KP, Li YF, Hirooka Y (2001). Role of nitric oxide in central sympathetic outflow. Exp Biol Med, Vol. 226, pp. $814-824$.

Patti G, Chello M, Pasceri V, et al (2006). Protection from procedural myocardial injury by atorvastatin is associated with lower levels of adhesion molecules after percutaneous coronary intervention. J Am Coll Cardiol, Vol. 48, pp. 1560 -6.

Patti G, Cannon C, Murphy SA et al (2011). Clinical benefit of statin pretreatment in patients undergoing percutaneous coronary intervention. A collaborative patient-level meta-analysis of 13 randomized studies. Circulation, Vol 123, pp 1622-1632.

Pigott R, Dillon LP, Hemingway IH et al. (1992). Soluble forms of ICAM-1 and VCAM-1 are present in the supernatants of cytokine activated cultured endothelial cells. Biochem Biophys Res Comm, Vol. 187, pp. 584-9.

Pliquett RU, Cornish KG, Peuler JD, Zucker IH (2003). Simvastatin normalizes Autonomic neural control in experimental heart failure. Circulation, Vol. 107, pp.2493 - 2498.

Rasmussen LM, Hansen PR, Nabipour MT, et al. (2001). Diverse effects of inhibition of 3hydroxy-3-methylglutaryl-CoA reductase on the expression of VCAM-1 and Eselectin in endothelial cells. Biochem J, Vol. 360, pp. 363-370.

Ray KK \&Cannon CP (2005). Early Time to Benefit with Intensive Statin Treatment: Could It Be the Pleiotropic Effects? Am J Cardiol, Vol. 96 [suppl F], pp. 54F-60F

Ray KK, Morrow DA, Shui A, et al (2006). Relation between soluble intercellular adhesion molecule-1, statin therapy, and long-term risk of clinical cardiovascular events in patients with previous acute coronary syndrome (from PROVE IT-TIMI 22). Am J Cardiol, Vol. 98, pp.861 -5.

Ridker PM, Cushman M, Stampfer MJ, Tracy RP, Hennekens CH (1997). Inflammation, aspirin, and the risk of cardiovascular disease in apparently healthy men. $\mathrm{N} \mathrm{Engl} \mathrm{J}$ Med, Vol. 336, pp. 973-979.

Ridker PM, Hennekens CH, Roitman-Johnson B, et al. (1998). Plasma concentration of soluble intercellular adhesion molecule 1 and risks of future myocardial infarction in apparently healthy men. Lancet, Vol. 351, pp. 88-92.

Ridker PM, Hennekens CH, Buring JE, Rifai N (2000). C-reactive protein and other markers of inflammation in the prediction of cardiovascular disease in women. New Engl J Med , Vol. 342, pp. 836-43.

Ridker PM, Cannon CP, Morrow D, et al. (2005). Pravastatin or Atorvastatin Evaluation and Infection Therapy-Thrombolysis in Myocardial Infarction 22 (PROVE IT-TIMI 22) Investigators. C-reactive protein levels and outcomes after statin therapy. $\mathrm{N} \mathrm{Engl} \mathrm{J}$ Med, Vol. 352, pp. 20-28

Schwartz PJ, Vanoli E, Stramba-Badiale M, et al (1988). Autonomic mechanisms and sudden death: new insights from analysis of baroreceptor reflexes in conscious dogs with and without a myocardial infarction. Circulation, Vol. 78, pp. 969-79.

Seljeflot I, Tonstad S, Hjermann I, et al (2002). Reduced expression of endothelial cell markers after 1 year treatment with simvastatin and atorvastatin in patients with coronary heart disease. Atherosclerosis, Vol. 162, pp. 179 - 85. 
Task Force of the European Society of Cardiology and the North American Society of Pacing and Electrophysiology (1996). Heart rate variability: standards of measurement, physiological interpretation and clinical use. Circulation, Vol. 93, pp.1043-65.

Tracey KJ (2002). The inflammatory reflex. Nature, Vol. 420, pp. 853- 859.

Tsuji H, Venditti FJ Jr, Manders ES, et al (1996). Determinants of heart rate variability. J Am Coll Cardiol, Vol. 28, pp. 1539-46.

Van Assche G\& Rutgeerts P. (2005). Physiological basis for novel drug therapies used to treat the inflammatory bowel diseases. I. Immunology and therapeutic potential of antiadhesion molecule therapy in inflammatory bowel disease. Am J Physiol Gastrointest Liver Physiol, Vol. 288(suppl), pp. G169-G174.

Wang H, Yu M, Ochani M, et al (2003). Nicotinic acetylcholine receptor alpha7 subunit is an essential regulator of inflammation. Nature, Vol. 421, pp. $384-388$.

Weitz-Schmidt G, Welzenbach K, Brinkmann V, et al (2001). Statins selectively inhibit leukocyte function antigen-1 by binding to a novel regulatory integrin site. Nat Med, Vol. 7, pp. 687-92.

Wiklund O, Mattson-Hulten L, Hurt-Camejo E, et al (2002). Effects of simvastatin and atorvastatin on inflammatory markers in plasma. J Intern Med, Vol. 251, pp. 338 - 47.

Yoshida M, Sawada T, Ishii H, et al. (2001). HMG-CoA reductase inhibitor modulates monocyte-endothelial cell interaction under physiological flow conditions in vitro: involvement of Rho GTPase-dependent mechanism. Arterioscler Thromb Vasc Biol, Vol. 21, pp. 1165-1171. 


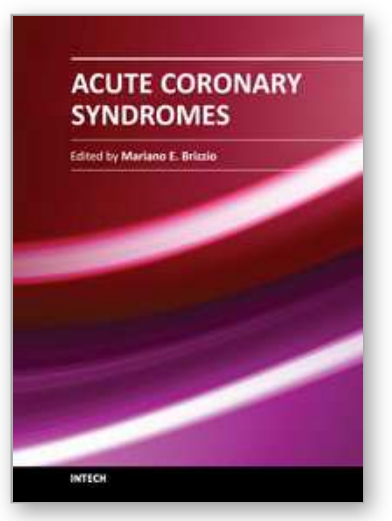

\author{
Acute Coronary Syndromes \\ Edited by Dr. Mariano Brizzio
}

ISBN 978-953-307-827-4

Hard cover, 214 pages

Publisher InTech

Published online 24, February, 2012

Published in print edition February, 2012

This book has been written with the intention of providing an up-to-the minute review of acute coronary syndromes. Atherosclerotic coronary disease is still a leading cause of death within developed countries and not surprisingly, is significantly rising in others. Over the past decade the treatment of these syndromes has changed dramatically. The introduction of novel therapies has impacted the outcomes and surviving rates in such a way that the medical community need to be up to date almost on a "daily bases". It is hoped that this book will provide a timely update on acute coronary syndromes and prove to be an invaluable resource for practitioners seeking new and innovative ways to deliver the best possible care to their patients.

\title{
How to reference
}

In order to correctly reference this scholarly work, feel free to copy and paste the following:

Arman Postadzhiyan, Anna Tzontcheva and Bojidar Finkov (2012). Markers of Endothelial Activation and Impaired Autonomic Function in Patients with Acute Coronary Syndromes - Potential Prognostic and Therapeutic Implication, Acute Coronary Syndromes, Dr. Mariano Brizzio (Ed.), ISBN: 978-953-307-827-4, InTech, Available from: http://www.intechopen.com/books/acute-coronary-syndromes/markers-of-endothelialactivation-and-impaired-autonomic-function-in-patients-with-acute-coronary-sy

\section{INTECH}

open science | open minds

\section{InTech Europe}

University Campus STeP Ri

Slavka Krautzeka 83/A

51000 Rijeka, Croatia

Phone: +385 (51) 770447

Fax: +385 (51) 686166

www.intechopen.com

\section{InTech China}

Unit 405, Office Block, Hotel Equatorial Shanghai

No.65, Yan An Road (West), Shanghai, 200040, China

中国上海市延安西路65号上海国际贵都大饭店办公楼 405 单元

Phone: +86-21-62489820

Fax: +86-21-62489821 
(C) 2012 The Author(s). Licensee IntechOpen. This is an open access article distributed under the terms of the Creative Commons Attribution 3.0 License, which permits unrestricted use, distribution, and reproduction in any medium, provided the original work is properly cited. 